\title{
Survival rate of patients with bladder cancer and its related factors in Kurdistan Province (2013-2018): a population-based study
}

Mozhdeh Amiri' ${ }^{1}$ Sofimajidpour Heshmatollah², Nader Esmaeilnasab³ ${ }^{3}$ Jamshid Khoubi ${ }^{4}$, Ebrahim Ghaderi ${ }^{3}$ and Daem Roshani ${ }^{3^{*}}$ (D)

\begin{abstract}
Background: Bladder cancer is one of the most common urinary tract cancers. This study aims to estimate the survival rate of patients with bladder cancer according to the Cox proportional hazards model based on some key relevant variables.
\end{abstract}

Methods: In this retrospective population-based cohort study that explores the survival of patients with bladder cancer and its related factors, we first collected demographic information and medical records of 321 patients with bladder cancer through in-person and telephone interviews. Then, in the analysis phase, Kaplan-Meier method and log-rank test were used to draw the survival curve, compare the groups, and explore the effect of risk factors on the patient survival rate using Cox proportional hazards model.

Results: The median survival rate of patients was 63.2 (54.7-72) months and one, three and five-year survival rates were $87 \%, 68 \%$ and $54 \%$, respectively. The results of multiple analyses using Cox's proportional hazards model revealed that variables of sex (male gender) $(\mathrm{HR}=11.8,95 \% \mathrm{Cl}: 0.4-100.7)$, more than 65 year of age $(\mathrm{HR}=4.1,95 \% \mathrm{Cl}$ : 0.4-11), occupation, income level, ( $\mathrm{HR}=0.4,95 \% \mathrm{Cl}$ : 0.2-0.8), well differentiated tumor grade ( $\mathrm{HR}=3.2,95 \% \mathrm{Cl}: 1.7-6)$ and disease stage influenced the survival rate of patients $(p<0.05)$.

Conclusion: The survival rate of patients with bladder cancer in Kurdistan province is relatively low. Given the impact of the disease stage on the survival rate, adequate access to appropriate diagnostic and treatment services as well as planning for screening and early diagnosis, especially in men, can increase the survival rate of patients.

Keywords: Survival rate, Bladder cancer, Population based, Cox proportional hazards model

\section{Background}

Bladder cancer is the most common urinary tract cancer and the ninth most prevalent cancer in both sexes worldwide $[1,2]$, accounting for $7 \%$ and $2 \%$ of new cases of cancers in men and women, respectively [3]. According

\footnotetext{
*Correspondence: d.roshani@muk.ac.ir

${ }^{3}$ Social Determinants of Health Research Center, Research Institute for Health Development, Kurdistan University of Medical Sciences, Sanandaj, Iran

Full list of author information is available at the end of the article
}

to statistical center of Iran, the ratio of bladder cancer mortality in men was 3.26 times higher than that of women between 2006 and 2010. The incidence of bladder cancer mortality was 1.12 and 1.09 per 100,000 people in 2006 and 2010, respectively, indicating that the trend was relatively stable. According to a 2015 study by Mahdavi et al., the death rate of bladder cancer increases with age, so that people above 70 years of age are more vulnerable to this disease [4]. Currently, bladder cancer mortality in Europe and the United States is declining due to the lower prevalence of smoking [5]. In 2016, 76,960 new 
cases and 16,390 deaths related to bladder cancer were reported in the United States, of which $76 \%$ of new cases were reported in men [6]. Women accounted for fewer cases, but factors like late diagnosis and advanced stages of the disease decreased their survival rate [7-11]. Bladder cancer is the second and the third most common cancer among men in Markazi and Kurdistan province, respectively [12, 13]. Studies on bladder cancer have linked several factors, including occupation, smoking, and sex to the higher prevalence of the disease [11, 14, 15 .

The survival rate index is defined as the proportion of cancer patients who survive over a given period of time after diagnosis. Several variables, such as cancer histology and stage, as well as the availability of treatment, affect the survival of the disease [18]. According to the results of our study, despite the rising disease incidence in Iran, there is a paucity of population-based research on the survival rate of patients with bladder cancer in Iran, and most of studies in this field have focused on the cancer trend and epidemiological analysis [12, 16-18].

Hence, the aim of the present study is to estimate the survival rate of bladder cancer patients based on Cox's proportional hazards model and to explore the variables affecting survival rates based on population-based information derived from Kurdistan province. The findings can significant contribute to the health system planning, timely treatment, patient survival and quality of life.

\section{Methods}

The present study is a retrospective population-based cohort study conducted in Kurdistan Province from 2013 to 2018. In the first stage, the information on patients diagnosed with bladder cancer was collected by reviewing all cases recorded in cancer registry at the Provincial Health Department, the Cancer Registration Center and the Provincial Mortality Registration Center. In the next step, demographic information (including: gender, age at diagnosis, marital status, place of residence, occupation, level of education, social status, smoking, family history and exposure to toxins and pesticides) and medical and pathological information (including stage of disease, tumor differentiation grade, treatment method, histology, diagnosis method and comorbidity) were collected through interviews, questionnaires and the review of medical records.

Patient information was recorded based on the ICDL10 International Classification (codes C67.0-C67.9). Given that all diagnosed patients in the study were chosen over a 6-year period from 2013 to 2018, the research was undertaken as a population census in Kurdistan province. In this study, of 341 patients diagnosed with bladder cancer, 12 (3.5\%) refused to participate in the study, and $8(2.3 \%)$ could not be reached. Hence, finally, 321 subjects were including in the study and their information was recorded. The cause and date of patients' deaths were recorded based on inquiries from the family and death certificates. Patients who were lost to the follow-up or died of bladder cancer were excluded from the study.

\section{Statistical analysis}

To determine the relationship between study variables and bladder cancer survival, STATA V.14 statistical software, Kaplan-Meier nonparametric method, and the log-rank test were used. For all variables, the survival curve was drawn and the variables with $p$ values $<0.2$ in the log-rank test were included in Cox proportional hazards model to estimate the effect of multiple variables on the survival rate by calculating the hazard ratio (HR) at a significant level of less than 0.05 . To calculate the total survival rate and one, three and five-year survival rates, the life table (monthly) was used over 1 to 5 - year period. Three methods of scaled Schoenfeld residuals, the hazard $\log$ cumulative and goodness of fit were used to assess the appropriateness of the hazards.

\section{Results}

In this study, the survival rate analysis was conducted for 321 patients with bladder cancer, of which $82.2 \%$ were male and $17.7 \%$ were female. Also, $77 \%$ of patients lived in urban areas, $87.8 \%$ were married and $53.9 \%$ were above 65 years of age. During the study period, 96 out of 321 participants passed away, 86 due to bladder cancer and 10 due to other causes. According to the results, the overall median survival of patients was 63.2(54.7-72) months and the mean survival (47.1-53.7) was $50.4 \pm 1.7$ months. Also, the one to five-year survival rates were $87 \%, 76 \%$, $68 \%, 61 \%$ and $54 \%$, respectively (Fig. 1 ).

Table 1 shows one-year, two-year, three-year and fiveyear survival rates for each variable using the life table, as well as $p$ values obtained from the log-rank test.

According to Table 1, the survival rate was higher in women than in men, and according to the log-rank test, the survival curve was not significantly different between the subgroups $(p<0.05)$. Moreover, survival rates were lower in single patients, patients above 65 years of age, and patients living in rural areas. Survival rates in retired and unemployed patients were higher than other groups. The literate and high-income patients also had higher survival rates. In this study, smoking, supplementary insurance, and family history were not statistically significant.

As shown in Table 1, patients at early disease stage who did not have an underlying disease, had a poorly differentiated tumor grade, and their histology was urothelial carcinoma had a higher survival rate. However, the 


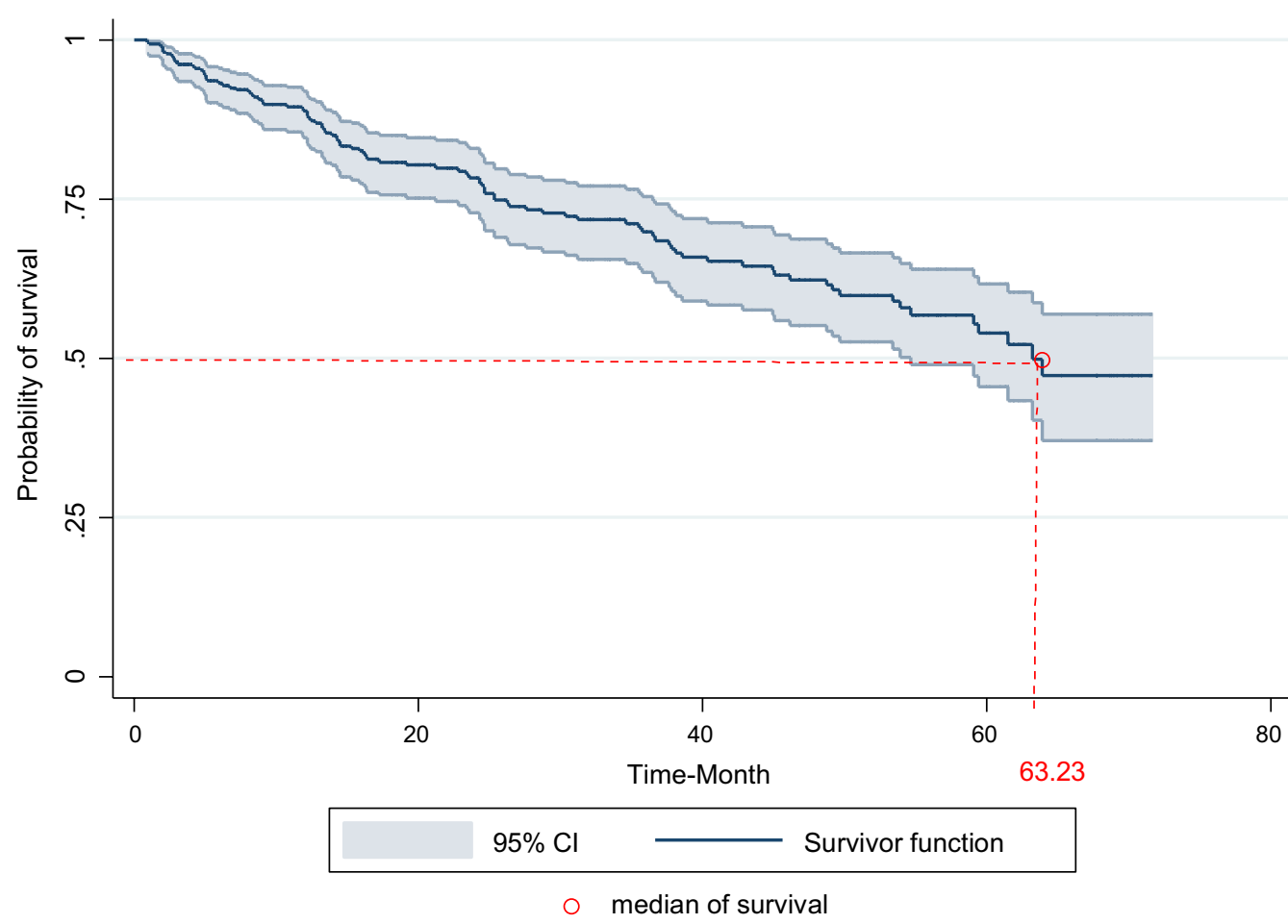

Fig. 1 Survival rate of patients treated with bladder cancer in Kurdistan province (2013-2018) (Kaplan-Meier). Cl=confidence interval, $\mathrm{BC}=$ bladder cancer

survival rate was not significantly different with regard to the method of diagnosis, type of treatment and exposure to poisons and pesticides. According to the results, group curves, gender $(p=0.044)$, age at diagnosis $(p<0.001)$, residence $(p<0.001)$, marital status $(p<0.001)$, level of education $(p=0.002)$, occupation $(p=0.008)$, socioeconomic status $(p<0.001)$, disease stage $(p<0.001)$, histology $(p=0.04)$ and tumor grade differentiation $(p<0.001)$ were significantly different. Moreover, the curves of the supplementary insurance, smoking, method of diagnosis, family history and underlying disease were not significantly different patients $(p<0.05)$ (Table 1$)$.

In the multivariate analysis, using Cox's proportional hazards, variables of gender, age groups, residence, marital status, level of education, occupation, disease stage, histology, treatment method, differentiation grade, and socioeconomic status were incorporated in the final model of Cox's proportional hazards model $(p<0.2)$. The results of the final model revealed that the hazard ratio was significantly higher in men than in women ( $\mathrm{HR}=11.8,95 \% \mathrm{CI}$ : 0.4-100.7). Moreover, the hazard ratio increased with age $(\mathrm{HR}=4.1,95 \% \mathrm{CI}$ : $1.5-$ 11.1) and patients from a high socioeconomic background had a lower hazard ratio than those from a poor socioeconomic background ( $\mathrm{HR}=0.4,95 \% \mathrm{CI}$ : $0.2-$ $0.8)$. The hazard ratio of patients at Stage II $(H R=1.5$,
95\% CI: 0.7-2.9), Stage III (HR $=2.8,95 \%$ CI: $1.34-5.8)$ and Stage IV $(\mathrm{HR}=6.4,95 \% \mathrm{CI}: 2.1-19.2)$ was higher than Stage V. Also, the hazard ratio growth at Stages III and IV was significantly different than Stage I, but it was not the case for Stages I and II $(p<0.05)$.

Moreover, the hazard ratio at well differentiated grade was greater than the poorly differentiated tumor grade $(\mathrm{HR}=3.25$, 95\% CI: 1.7-6). Patients with an office job $(\mathrm{HR}=4.9,95 \% \mathrm{CI}: 1.7-13.9)$ and workers $(\mathrm{HR}=2.6$, 95\% CI: 1.1-6.2) had a higher hazard ratio than retired and unemployed patients. Meanwhile, the variables of residence, marital status, level of education, type of histology and treatment method were not significantly related to the survival rate of patients $(p<0.05)$ (Table 2).

Figure 1 shows that the median survival of patients with bladder cancer in Kurdistan province was 63.2(54.7-72) months.

The survival rate of patients with bladder cancer versus sex in study participants shows that the five-year survival is higher in women than in men (Fig. 2). Also, the survival rate of patients with bladder cancer versus age at diagnosis shows that the five-year survival in participants with $\geq 65$ year is less than the others (Fig. 3).

Figure 4 shows that the five-year survival rate in patients from rich $(74 \%)$, moderate $(61 \%)$, and poor (34\%) 
Table 1 Demographic and clinical characteristics of patients diagnosed with bladder cancer in terms of mean survival rate using Kaplan-Meier method

\begin{tabular}{|c|c|c|c|c|}
\hline Characteristic & Category & Frequency (\%) & $\begin{array}{l}\text { Mean survival } \\
\text { per month }(95 \% \mathrm{Cl})\end{array}$ & $p^{*}$ \\
\hline \multirow[t]{2}{*}{ Sex } & Female & $57(17.7)$ & $57.4(50-64.8)$ & 0.04 \\
\hline & male & $264(82.2)$ & $48.9(45.2-52.6)$ & \\
\hline \multirow[t]{3}{*}{ Age at diagnosis } & $\leq 50 y$ & $43(13.4)$ & $60.3(53.1-67.5)$ & $<0.001$ \\
\hline & $51-64 y$ & $105(32.7)$ & $55.8(50.5-61)$ & \\
\hline & $\geq 65 y$ & $173(53.9)$ & $44.3(39.7-48.9)$ & \\
\hline \multirow[t]{2}{*}{ Marital status } & Single (unmarried, divorced, widow/widower) & $39(12.1)$ & $32.7(23.8-41.5)$ & $<0.001$ \\
\hline & Married & $282(87.8)$ & $52.9(49.5-56.4)$ & \\
\hline \multirow[t]{2}{*}{ Residence } & Rural & $74(23.5)$ & $41.7(35.3-47.9)$ & $<0.001$ \\
\hline & Urban & $247(76.9)$ & $53.9(50.2-57.7)$ & \\
\hline \multirow[t]{6}{*}{ Occupation } & Unemployed/Retired & $67(20.8)$ & $58.9(52.5-65.3)$ & 0.008 \\
\hline & Housewife & $47(14.6)$ & $56.2(47.9-64.5)$ & \\
\hline & Worker & $53(16.5)$ & $48.8(39.6-57.9)$ & \\
\hline & Self-employed & $66(20.5)$ & $48.1(40.5-55.7)$ & \\
\hline & Office job & $27(8.4)$ & $47.7(39.3-55.9)$ & \\
\hline & Agriculturist & $61(19.0)$ & $41.6(34.9-48.2)$ & \\
\hline \multirow[t]{2}{*}{ Education } & Illiterate & $158(49.2)$ & $45.3(40.5-50.1)$ & 0.001 \\
\hline & Literate & $163(50.7)$ & $55.8(51.4-60.2)$ & \\
\hline \multirow[t]{3}{*}{ Socioeconomic status } & Poor & $106(33.1)$ & $42.4(36.9-47.8)$ & $<0.001$ \\
\hline & Moderate & $107(33.4)$ & $52.3(46.5-57.9)$ & \\
\hline & Rich & $107(33.4)$ & $58.5(53.2-63.8)$ & \\
\hline \multirow[t]{2}{*}{ Smoking } & No & $172(53.5)$ & $51.7(46.6-56.7)$ & 0.5 \\
\hline & Yes & $149(46.4)$ & $49.4(45-53.7)$ & \\
\hline \multirow[t]{2}{*}{ Family history of $\mathrm{BC}$} & No & $301(93.7)$ & $50.0(46.5-53.4)$ & 0.5 \\
\hline & Yes & $20(6.2)$ & $54.6(43.3-65.9)$ & \\
\hline \multirow[t]{2}{*}{ Comorbidity } & No & $205(63.8)$ & $50.8(46.7-54.8)$ & 0.5 \\
\hline & Yes & $116(34.1)$ & $49.3(43.6-54.9)$ & \\
\hline \multirow[t]{4}{*}{ TNM stage } & 1 & $210(65.4)$ & $58.5(55-62)$ & $<0.001$ \\
\hline & $\|$ & $74(23)$ & $44.5(37.2-51.7)$ & \\
\hline & III & $29(9)$ & $21.7(12.9-30.4)$ & \\
\hline & IV & $8(2.5)$ & $21.3(8.9-33.6)$ & \\
\hline \multirow[t]{2}{*}{ Grade } & Poorly differentiated & $217(67.6)$ & $59.7(56.3-62.9)$ & $<0.001$ \\
\hline & Well differentiated & $104(32.4)$ & $31.6(25.8-37.3)$ & \\
\hline \multirow[t]{4}{*}{ Treatment } & Radiation therapy & $13(4)$ & $48.2(34.5-61.7)$ & 0.05 \\
\hline & Surgery & $207(64.5)$ & $53.6(49.6-57.5)$ & \\
\hline & Chemotherapy & $10(3.1)$ & $31.9(20.3-43.5)$ & \\
\hline & $\begin{array}{l}\text { Combinational treatment (Surgery, Radiotherapy, } \\
\text { Chemotherapy or Immunotherapy) }\end{array}$ & $85(26.4)$ & $44.5(38-50.8)$ & \\
\hline \multirow[t]{3}{*}{ Histology } & Adenocarcinoma & $10(3.1)$ & $34.7(24.8-44.5)$ & 0.03 \\
\hline & Squamous cell carcinoma & $7(2.1)$ & $24.9(3.7-46)$ & \\
\hline & Urothelial carcinoma & $304(94.7)$ & $51.3(47.9-54.7)$ & \\
\hline \multirow[t]{4}{*}{ Method of diagnosis } & Urinalysis and ultrasound & $55(17.1)$ & $52.9(46.5-59.3)$ & 0.5 \\
\hline & Cystoscopy and biopsy & $55(17.1)$ & $45.4(37.7-53)$ & \\
\hline & Biopsy and ultrasound & $35(10.9)$ & $50.0(40.6-59.3)$ & \\
\hline & Combinational method of diagnosis & $176(54.8)$ & $50.8(46.1-55.6)$ & \\
\hline \multirow[t]{2}{*}{ Poison and pesticides exposure } & Yes & $64(19.9)$ & $49.9(43.5-56.4)$ & 0.9 \\
\hline & No & $257(80)$ & $50.5(46.7-54.3)$ & \\
\hline
\end{tabular}

$B C$ bladder cancer

*Log-rank test- $p$ value 
socioeconomic backgrounds, according to the log-rank test, is significantly different $(p<0.001)$.

Figure 5 shows the five-year survival rate in patients at Stage I (67\%), Stage II (45\%) and Stage III (15\%), according to the log-rank test, is not significantly different $(p<0.001)$.

\section{Discussion}

The one-year, three-year and five-year survival rates of patients with bladder cancer in Kurdistan province resembled the survival rates of patients in Shiraz province, as reported by Mohammad Beigi et al. The oneyear, three-year, five-year, and ten-year survival rates of patients in their study were $0.9,0.7,0.6$, and 0.2 , respectively [19].

According to the American Cancer Society (ACS) in 2016, the five-year, ten-year, and fifteen-year survival rates at all stages of bladder cancer are $77 \%, 70 \%$, and $65 \%$, respectively [20]. This suggests that the five-year survival rate of bladder cancer patients in Kurdistan province $(54 \%)$ in this study is lower than in developed countries. However, the median survival of patients was estimated to be 63.23 months, which is higher than the value reported by Benjamin WF et al. (Median OS $=14$, 95\% CI: $13.5-14.5$ ) [21]. It is probably due to early diagnosis of the disease because $65.4 \%$ of patients were identified at Stage I and 23.05\% at Stage II.

In this study, the history of smoking was not significantly related to the survival rate of patients. Most patients had a history of smoking at young age but had abandoned smoking after a while or due to the bladder cancer. This could be attributed to the effect of smoking cessation followed by the reduced devastating effect of the disease. Our findings are consistent with those reported by Mohammad Beigi et al., who did not report a significant relationship between smoking and survival rates [19]. This results illustrated that just as reduced smoking decreased the incidence of bladder cancer, smoking cessation also increased the survival of patients with bladder cancer [22].

In the present study, age and income level influenced the survival rate of patients with bladder cancer $(p<0.05)$, which is aligned with the study of Joshua Lara et al. In their study, the risk of death in adolescents and youths was lower than older people ( $\mathrm{HR}=0.4,95 \% \mathrm{CI}$ : $0.3-0.5)$. In adolescents and young people from poor socioeconomic background, the specific survival rate $(\mathrm{HR}=7.1$, $p<0.001)$ and the overall survival rate $(\mathrm{HR}=5, p<0.001)$ were statistically significant [23].

According to the results, the survival rate was higher in women than in men, which is in conflict with the findings reported by Stephen B.W. et al. This could be assigned to
Table 2 Univariate and multivariate Cox proportional hazards model for the overall survival of patients with bladder cancer

\begin{tabular}{|c|c|c|c|c|}
\hline & \multicolumn{2}{|c|}{ Univariate model } & \multicolumn{2}{|c|}{ Multivariate model } \\
\hline & HR (95\%) & $p$ value & HR (95\%) & $p$ value \\
\hline \multicolumn{5}{|l|}{ Sex } \\
\hline Female & 1 & - & 1 & - \\
\hline Male & $1.9(1-3.7)$ & 0.04 & $11.8(1.3-100.7)$ & 0.02 \\
\hline \multicolumn{5}{|l|}{ Age } \\
\hline$\leq 50$ & 1 & - & 1 & \\
\hline $51-64$ & $1.6(0.6-4)$ & 0.27 & $1.1(0.4-3.1)$ & 0.8 \\
\hline$\geq 65$ & $3.3(1.4-7.5)$ & 0.005 & $4.1(1.5-11)$ & 0.004 \\
\hline \multicolumn{5}{|l|}{ Marital status } \\
\hline Single* & 1 & - & 1 & - \\
\hline Married & $0.36(0.2-0.6)$ & $<0.001$ & $0.7(0.3-1.3)$ & 0.3 \\
\hline \multicolumn{5}{|l|}{ Residence } \\
\hline Rural & 1 & - & 1 & - \\
\hline Urban & $0.5(0.3-0.7)$ & 0.001 & $0.8(0.4-1.6)$ & 0.5 \\
\hline \multicolumn{5}{|l|}{ Occupation } \\
\hline Unemployed/Retired & 1 & - & 1 & - \\
\hline Housewife & $1.2(0.5-26.8)$ & 0.6 & $11.3(1.1-116.8)$ & 0.04 \\
\hline Worker & $2.2(1-4.7)$ & 0.04 & $2.6(1.1-6.2)$ & 0.03 \\
\hline Self-employed & $2.2(1.1-4.4)$ & 0.03 & $3.3(1.5-7.1)$ & 0.002 \\
\hline Office job & $1.8(0.7-4.4)$ & 0.19 & $4.9(1.7-13.9)$ & 0.003 \\
\hline Agriculturist & $3.1(1.6-6.1)$ & 0.001 & $1.8(0.7-4.4)$ & 0.2 \\
\hline \multicolumn{5}{|l|}{ Education } \\
\hline Illiterate & 1 & - & 1 & - \\
\hline Literate & $0.5(0.3-0.8)$ & 0.003 & $1.1(0.6-2)$ & 0.8 \\
\hline \multicolumn{5}{|l|}{ Socioeconomic status } \\
\hline Poor & 1 & - & 1 & - \\
\hline Moderate & $0.6(0.3-0.9)$ & 0.02 & $0.5(0.3-1)$ & 0.06 \\
\hline Rich & $0.35(0.2-0.6)$ & $<0.001$ & $0.4(0.2-0.8)$ & 0.01 \\
\hline \multicolumn{5}{|l|}{ TNM stage } \\
\hline 1 & 1 & - & 1 & - \\
\hline$\|$ & $2.4(1.5-4)$ & $<0.001$ & $1.5(0.7-2.9)$ & 0.2 \\
\hline III & $7.9(4.7-13.4)$ & $<0.001$ & $2.8(1.3-5.8)$ & 0.006 \\
\hline IV & $7.3(3.2-16.6)$ & $<0.001$ & $6.4(2.1-19.3)$ & 0.001 \\
\hline \multicolumn{5}{|l|}{ Grade } \\
\hline Poorly differentiated & 1 & - & 1 & - \\
\hline Well differentiated & $5.2(3.4-7.9)$ & $<0.001$ & $3.2(1.7-6)$ & $<0.001$ \\
\hline \multicolumn{5}{|l|}{ Treatment } \\
\hline Radiation therapy & 1 & - & 1 & - \\
\hline Surgery & $0.8(0.3-2.1)$ & 0.6 & $0.9(0.3-2.6)$ & 0.8 \\
\hline Chemotherapy & $1.7(0.4-6.6)$ & 0.4 & $1.5(0.3-6.2)$ & 0.6 \\
\hline $\begin{array}{l}\text { Combinational treat- } \\
\text { ment }\end{array}$ & $1.3(0.4-3.7)$ & 0.6 & $0.9(0.5-5)$ & 0.4 \\
\hline \multicolumn{5}{|l|}{ Histologic type } \\
\hline Adenocarcinoma & 1 & - & 1 & - \\
\hline $\begin{array}{l}\text { Squamous cell } \\
\text { carcinoma }\end{array}$ & $1.3(0.3-5.1)$ & 0.7 & $4.7(0.8-26.8)$ & 0.08 \\
\hline Urothelial carcinoma & $0.46(0.19-1)$ & 0.06 & $1.6(0.5-4.5)$ & 0.4 \\
\hline
\end{tabular}

$H R$ hazard ratio, $\mathrm{Cl}$ confidence interval

*Unmarried, divorced, widow/widower 


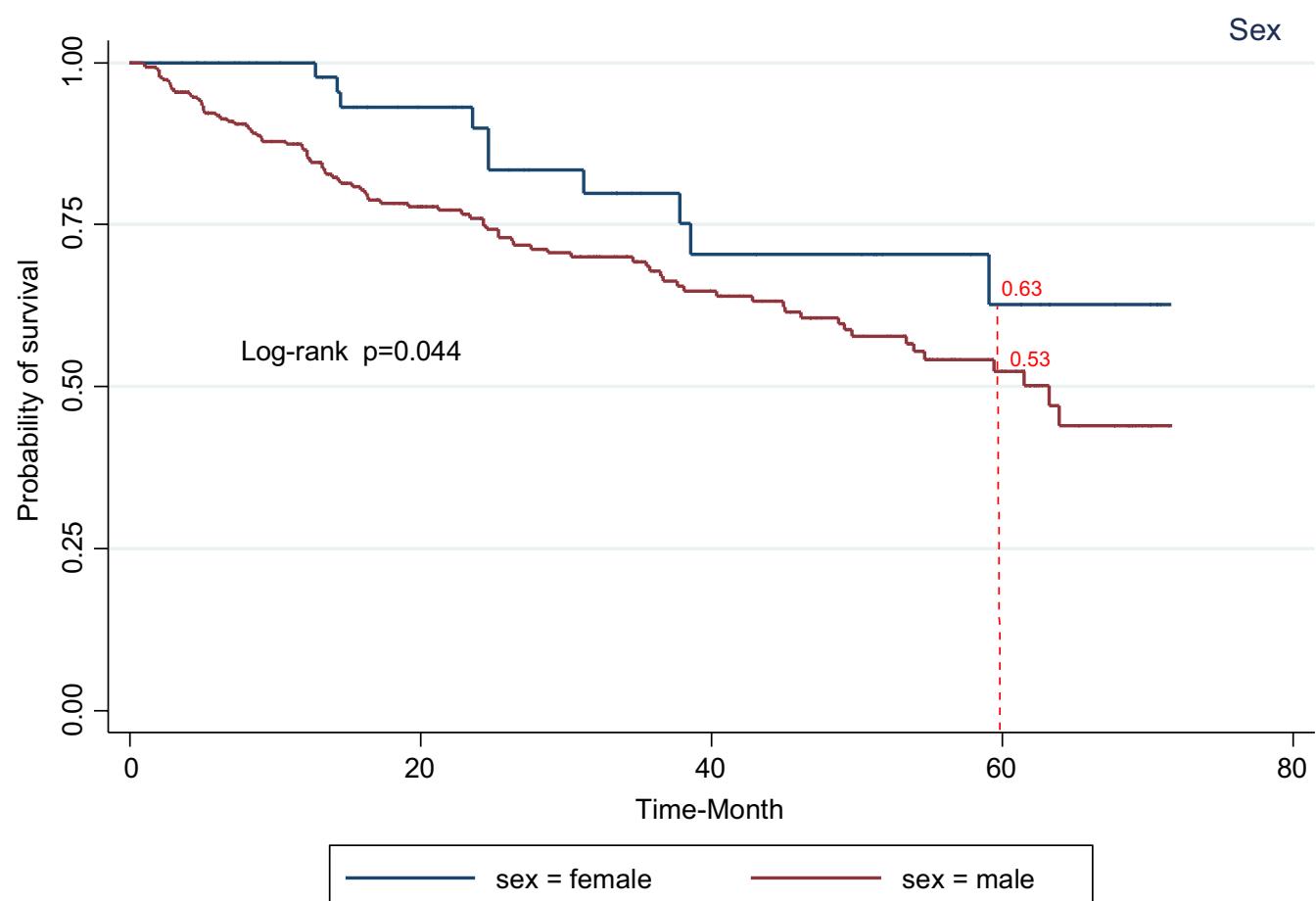

Fig. 2 Kaplan-Meier curves of survival in patients with bladder cancer versus sex

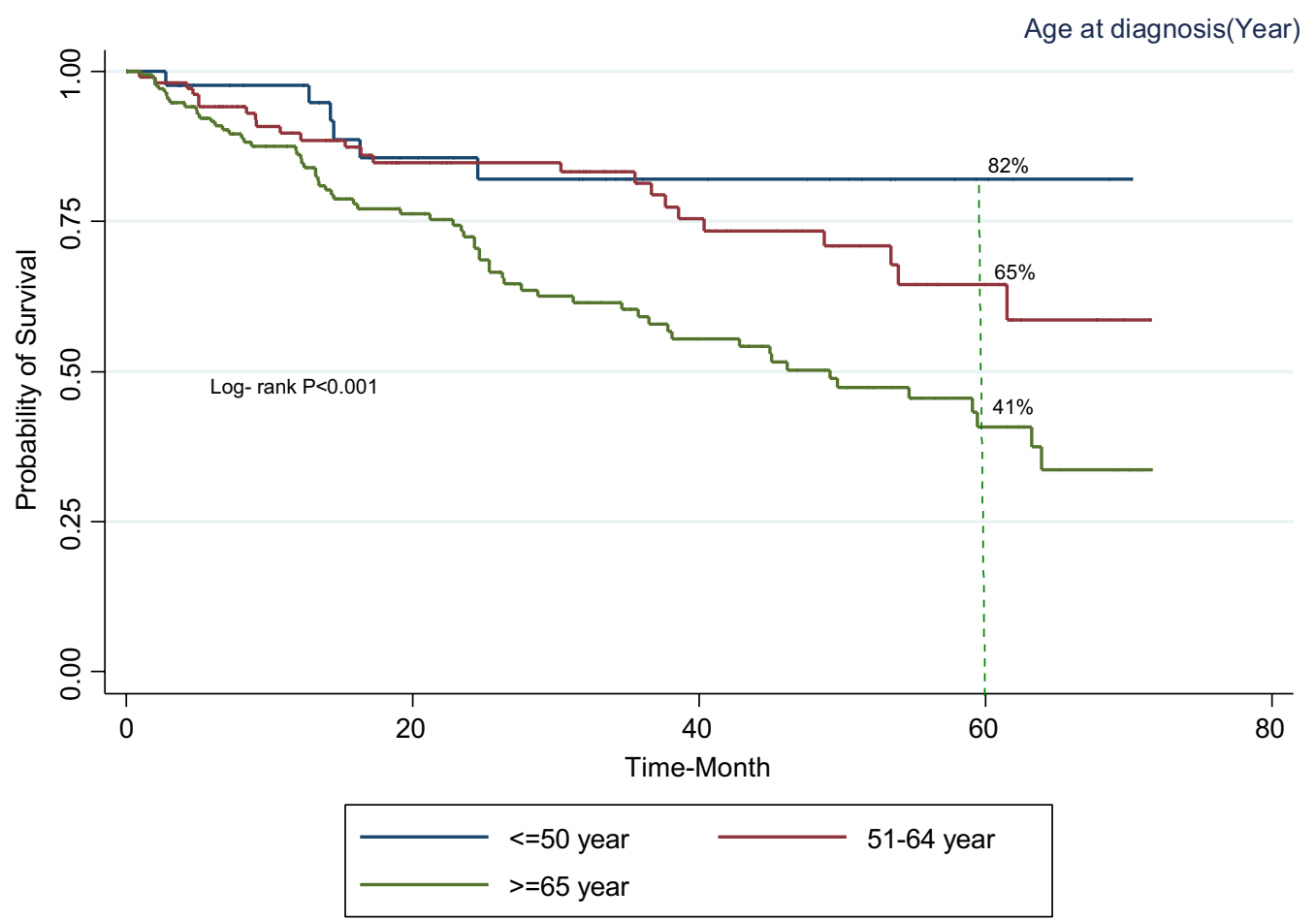

Fig. 3 Kaplan-Meier curves of the survival of patients with bladder cancer versus age at diagnosis 


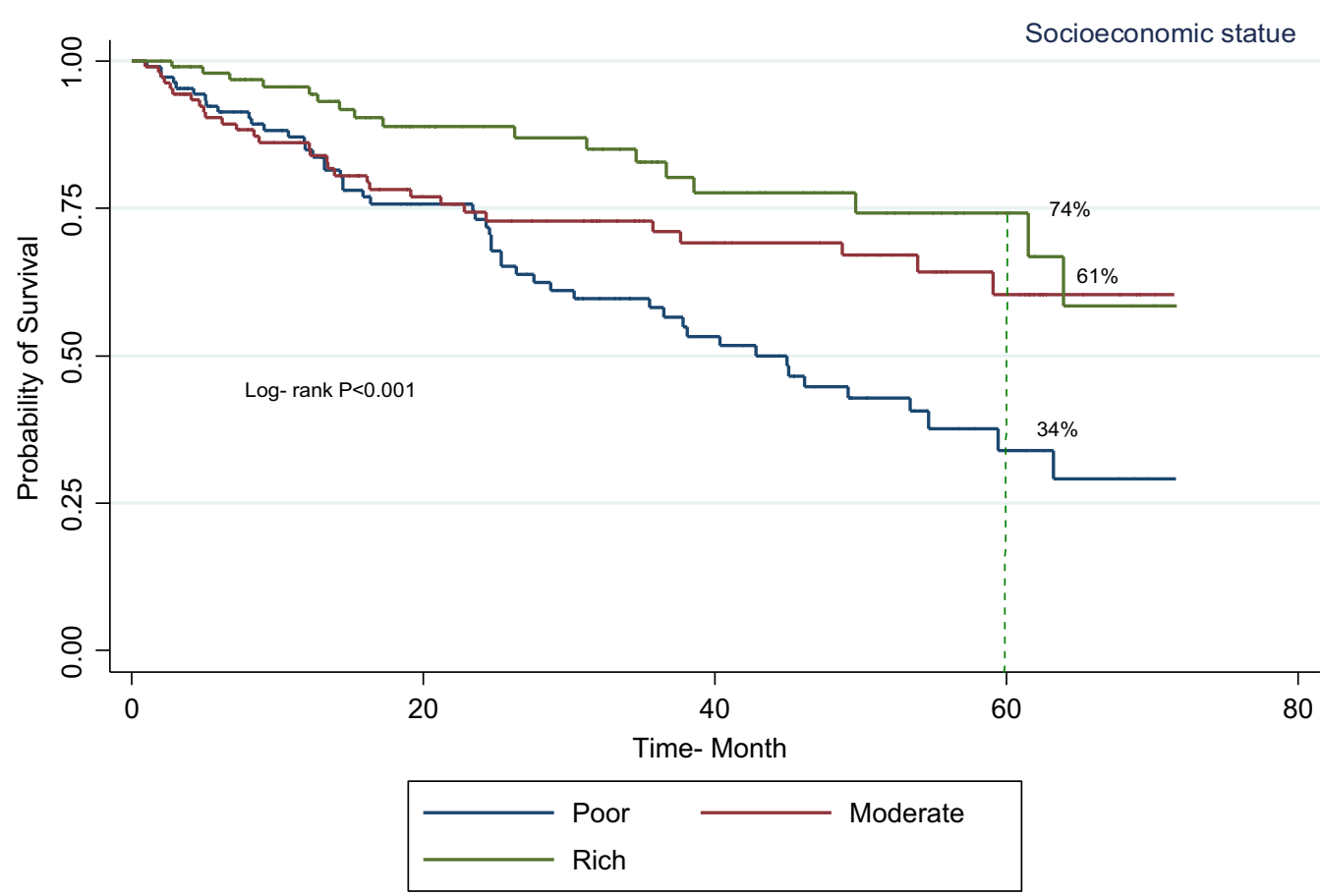

Fig. 4 Kaplan-Meier curves of the survival of patients with bladder cancer versus socioeconomic status

the early detection of the disease and the higher commitment of women with bladder cancer to follow-ups. However, in both studies, the incidence was higher in men. Furthermore, old age, tumor stage and single marital status were found to be significantly related to the lower survival rate $(p<0.05)$. In this study, we observed that the diagnosis of the disease at lower stage was associated with the higher survival of patients, which is consistent with the study of Stephen B.W. [24].

Survival rates were also higher in urban residents than in rural areas, which can be attributed to the greater access to healthcare services and follow-ups. For many cancers, survival is considerably lower in rural areas than in urban areas $(p<0.05)$ [25].

Khoubi et al. introduced exposure to poisons and pesticides as a risk factor for bladder cancer, but in the present study, the history of exposure to pesticides was not significantly correlated with the survival rate of patients with bladder cancer $(p>0.05)$ [26]. We found that most farmers had attended Agricultural Jihad's training classes and put on personal protective gears during spraying. There was a statistically significant association between housework and increased risk of bladder cancer in women, which is in agreement with the findings of Khoubi et al. (ISCO 5152, OR $=5.9,95 \% \mathrm{CI}=1.04-34.3$ )
[26]. This is due to the fact that women are more likely to use detergents, cleaners and bleaches, and inhale oil fumes during frying and less likely to engage in physical activities. Our study also showed that an office job and self-employment were significantly correlated with the survival rate $(p<0.05)$.

The univariate and multivariate Cox regression analysis did not reveal a significant relationship between treatment method and survival rate, but in the study of Mark C. et al., the overall survival rate improved in chemotherapy patients $(\mathrm{HR}=0.7,95 \% \mathrm{CI}: 0.6-0.9, p<0.001)$ [27]. In this study, $64.9 \%$ of patients with bladder cancer underwent surgery and 3.1\% started chemotherapy, but the surgical procedure was not significantly correlated with the patient survival $(p<0.05)$. This aligns well with the study of Stephen BW et al. who did not report any associations between the survival of the elderly with radical cystectomy and sex at all stages $(\mathrm{HR}=1.07,95 \% \mathrm{CI}$ : $1.01-1.1, p=0.02$ ) [24].

Literacy was also linked to survival. Literate participants had a higher survival rate than the illiterate ones. This suggests that raising awareness and promoting health literacy can influence the survival rate of patients $(p<0.05)$. The survival rate was higher in married subjects than in the single subjects (never married, widower 


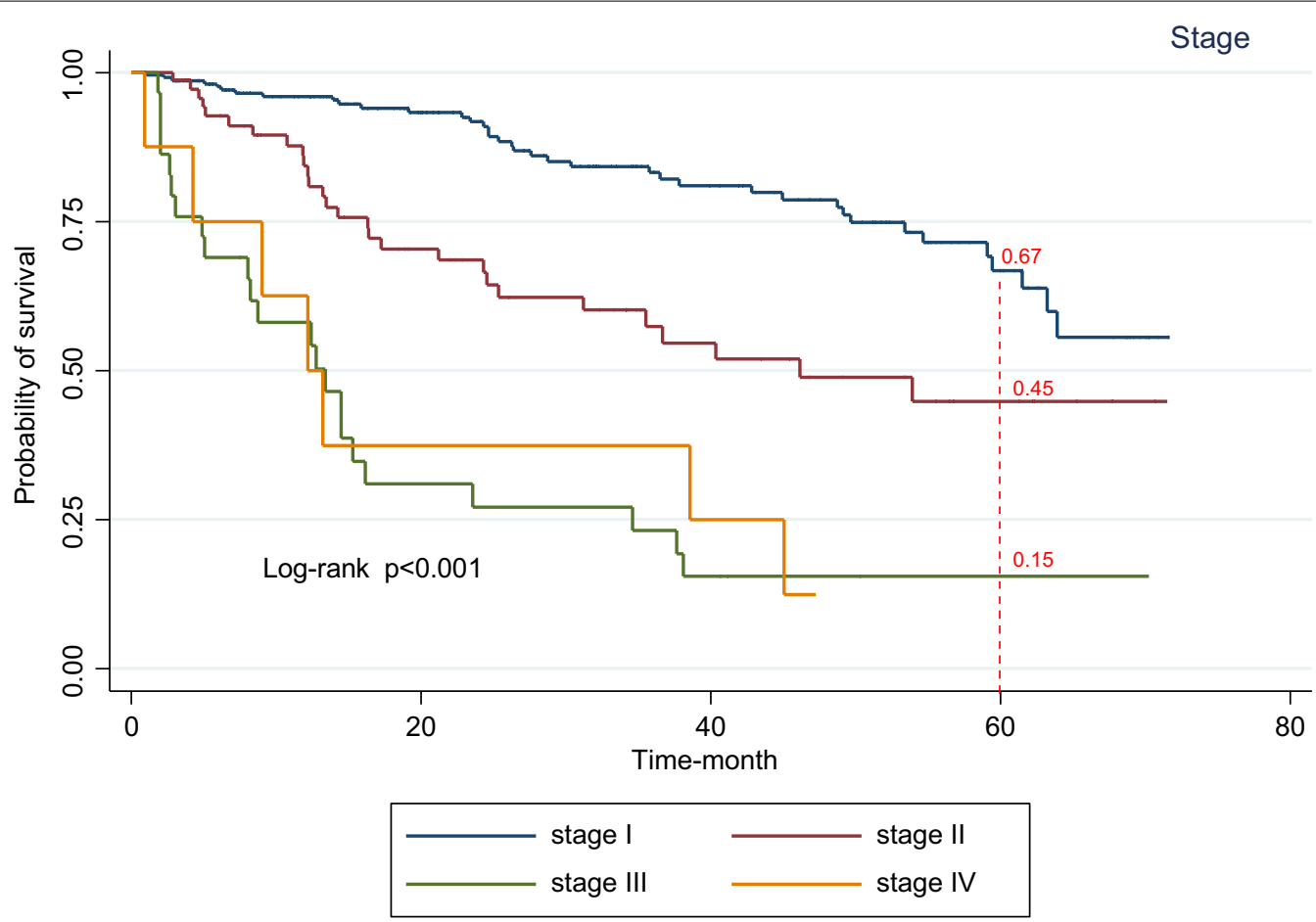

Fig. 5 Kaplan-Meier curves of the survival of patients with bladder cancer versus diagnosis stage

or divorced), which is in agreement with the study of Klapheke et al. [28].

Our study had a number of limitations including incompleteness of patients' medical records. The distinguishing point of this study is its population-based nature, which eliminates the problem of accessing hospital records and biases.

\section{Conclusion}

The results of this study demonstrated that the survival rate of patients with bladder cancer in Kurdistan province is relatively low due to lack of access to appropriate diagnostic and treatment services, lack of screening and early diagnosis and sloppy follow-ups, especially amongst men. Variables of gender, over 65 years of age, occupation, socioeconomic background, tumor differentiation grade, and disease stage affected patient survival rates. This suggests the importance of further planning for these factors to increase the survival of patients with bladder cancer.

\section{Acknowledgements}

This study was a research project in Kurdistan University of Medical Sciences. We would like to thank the National Cancer Registry in Kurdistan for providing data, as well as all those who were involved in the project and helped us collect data from across the country.

\section{Authors' contributions}

Data curtain: DR, MA, HS, NE, JK, EG. Formal analysis: DR, MA. Investigation: DR, $M A, H S$. Project administration: DR, MA. Writing - original draft: DR, MA. Writing - review \& editing: DR, MA, HS, NE, JK, EG. All authors read and approved the final manuscript.

\section{Funding}

This study was supported by Kurdistan University of Medical Sciences.

\section{Availability of data and materials}

The datasets used during the study could be provided by the corresponding author on reasonable request.

\section{Ethics approval and consent to participate}

The study protocol was approved by the Ethics Committee of Kurdistan University of Medical Sciences (ethics code: IR.MUK.REC.1397.343). The patients' recorded information were used as the primary source of data and therefore no consent was required for participation.

\section{Consent for publication}

Not applicable.

\section{Competing interests}

No direct or indirect commercial, personal, academic, political, religious or ethical incentive is associated with publishing this article.

\footnotetext{
Author details

${ }^{1}$ Department of Epidemiology and Biostatistics, Faculty of Medicine, Kurdistan University of Medical Sciences, Sanandaj, Iran. ${ }^{2}$ Department of Urology, Faculty of Medicine, Kurdistan University of Medical Sciences, Sanandaj, Iran.

${ }^{3}$ Social Determinants of Health Research Center, Research Institute for Health Development, Kurdistan University of Medical Sciences, Sanandaj, Iran. ${ }^{4}$ Environmental Health Research Center, Research Institute for Health Development, Kurdistan University of Medical Sciences, Sanandaj, Iran.
} 
Received: 27 July 2020 Accepted: 4 December 2020

Published online: 11 December 2020

\section{References}

1. Koosha A, Farahbakhsh M, Hakimi S, Abdolahi L, Golzari M, Farshad MS. Epidemiologic assessment of cancer disease in East Azerbaijan 2007. Med J Tabriz Univ Med Sci Health Serv. 2010;32(4):74-9.

2. Ploeg M, Aben KK, Kiemeney LA. The present and future burden of urinary bladder cancer in the world. World J Urol. 2009;27(3):289-93.

3. Salehi A, Khezri AA, Malekmakan L, Aminsharifi A. Epidemiologic status of bladder cancer in Shiraz, southern Iran. Asian Pac J Cancer Prev. 2011;12(5):1323-7.

4. Mahdavi S, Amoori N, Salehiniya H, Almasi Z, Enayatrad M. Trend of bladder cancer mortality in Iran (2006 to 2010). Int J Epidemiol Res. 2015;2(4):184-9.

5. Jemal A, Bray F, Center MM, Ferlay J, Ward E, Forman D. Global cancer statistics. CA: Cancer J Clin. 2011;61(2):69-90.

6. Miller KD, Siegel RL, Lin CC, Mariotto AB, Kramer JL, Rowland JH, Stein KD, Alteri R, Jemal A. Cancer treatment and survivorship statistics, 2016. CA: Cancer J Clin. 2016;66(4):271-89.

7. Fajkovic H, Halpern JA, Cha EK, Bahadori A, Chromecki TF, Karakiewicz PI, Breinl E, Merseburger AS, Shariat SF. Impact of gender on bladder cancer incidence, staging, and prognosis. World J Urol. 2011;29(4):457-63.

8. Mungan NA, Aben KK, Schoenberg MP, Visser O, Coebergh JW, Witjes JA, Kiemeney LA. Gender differences in stage-adjusted bladder cancer survival. Urology. 2000;55(6):876-80.

9. Kiemeney L, Mungan N, Aben K, Schoenberg M, Visser O, Coebergh $J$, et al. Gender differences in stage-adjusted bladder cancer survival. 2000;151(11):S68.

10. Najari BB, Rink M, Li PS, Karakiewicz PI, Scherr DS, Shabsigh R, Meryn S, Schlegel PN, Shariat SF. Sex disparities in cancer mortality: the risks of being a man in the United States. J Urol. 2013;189(4):1470-4.

11. Scosyrev E, Noyes K, Feng C, Messing E. Sex and racial differences in bladder cancer presentation and mortality in the US. Cancer. 2009;115(1):68-74.

12. Mohaghegh F, Hamta A. The study of cancer incidence and cancer registration in Markazi province between 2001-2006 and comparison with national statistics. Iran. J Arak Univ Med Sci. 2008;11(2):84-93.

13. Ahmad E, Ghasem KO, Dastoori P. Recurrence rate and prognostic factors of superficial bladder cancer in shiraz shahid faghihi hospital during the years 1998-2001.

14. Whelan P. Survival from bladder cancer in England and Wales up to 2001. British J Cancer. 2008;99(Suppl 1):S90.

15. Brookfield KF, Cheung MC, Gomez C, Yang R, Nieder AM, Lee DJ, Koniaris LG. Survival disparities among African American women with invasive bladder cancer in Florida. Cancer: Interdiscip Int J Am Cancer Soc. 2009;115(18):4196-209.
16. Nourafkan Z, Yavari P, Roshandel GH, Khalili D, Zayeri F. Estimation of survival rate of esophageal cancer and some of its determinants in Golestan province, north of Iran. Iran J Epidemiol. 2013;9(1):11-8.

17. Farahmand M, Khadem AF, Medhati M, Shokrpour N, Joulaei H, Mehrbani D. Trend of bladder cancer in Fars province, southern Iran, 2002-2006.

18. Toutounchi M, Mazdak H, Najafipour S, Soleymani B. Bladder cancer risk factors among Isfahan population: a case-control study.

19. Mohammadbeigi A, Rezaeian Zadeh A. Application of life table in survival analysis of patients with bladder cancer. Zahedan J Res Med Sci. 2011;13(3).

20. http://www.cancer-org 2016 [bladder cancer].

21. Fischer-Valuck BW, Rao YJ, Rudra S, Przybysz D, Germino E, Samson P, Baumann BC, Gay H, Michalski J. Treatment patterns and overall survival outcomes of octogenarians with muscle invasive cancer of the bladder: an analysis of the national cancer database. J Urol. 2018;199(2):416-23.

22. Cumberbatch MG, Jubber I, Black PC, Esperto F, Figueroa JD, Kamat AM, Kiemeney L, Lotan Y, Pang K, Silverman DT, Znaor A. Epidemiology of bladder cancer: a systematic review and contemporary update of risk factors in 2018. Eur Urol. 2018;74(6):784-95.

23. Lara J, Brunson A, Keegan TH, Malogolowkin M, Pan CX, Yap S, deVere White R. Determinants of survival for adolescents and young adults with urothelial bladder cancer: results from the california cancer registry. J Urol. 2016;196(5):1378-82.

24. Williams SB, Huo J, Dafashy TJ, Ghaffary CK, Baillargeon JG, Morales EE, Kim SP, Kuo YF, Orihuela E, Tyler DS, Freedland SJ. Survival differences among patients with bladder cancer according to sex: critical evaluation of radical cystectomy use and delay to treatment. In: Urologic oncology: seminars and original investigations, vol. 35, no. 10. Elsevier; 2017.

25. Chen W, Zheng R, Baade PD, Zhang S, Zeng H, Bray F, Jemal A, Yu XQ, He J. Cancer statistics in China, 2015. CA: Cancer J Clin. 2016;66(2):115-32.

26. Khoubi J, Pourabdian S, Mohebbi I, Tajvidi M, Zaroorian O, Giahi O. Association between the high risk occupations and bladder cancer in Iran: a case-control study. Int J Occup Med Environ Health. 2013;26(2):205-13.

27. Korpics MC, Block AM, Martin B, Hentz C, Gaynor ER, Henry E, Harkenrider $\mathrm{MM}$, Solanki AA. Concurrent chemotherapy is associated with improved survival in elderly patients with bladder cancer undergoing radiotherapy. Cancer. 2017;123(18):3524-31.

28. Klapheke A, Yap SA, Pan K, Cress RD. Sociodemographic disparities in chemotherapy treatment and impact on survival among patients with metastatic bladder cancer. In: Urologic oncology: seminars and original investigations, vol. 36, no. 6. Elsevier; 2018.

\section{Publisher's Note}

Springer Nature remains neutral with regard to jurisdictional claims in published maps and institutional affiliations.
Ready to submit your research? Choose BMC and benefit from:

- fast, convenient online submission

- thorough peer review by experienced researchers in your field

- rapid publication on acceptance

- support for research data, including large and complex data types

- gold Open Access which fosters wider collaboration and increased citations

- maximum visibility for your research: over $100 \mathrm{M}$ website views per year

At BMC, research is always in progress.

Learn more biomedcentral.com/submissions 